\title{
The Social Meaning of Midwifery
}


Related titles from Macmillan Education

The Midwifery Practice Series

eds Jo Alexander, Valerie Levy and Sarah Roch

Antenatal care

Intrapartum care

Postnatal care

Theory for Midwifery Practice, Rosamund Bryar 


\title{
The Social Meaning of Midwifery
}

\author{
Sheila C. Hunt \\ Head of Midwifery Education \\ Department of Nursing and Midwifery \\ University of Wales, Swansea \\ and \\ Anthea Symonds \\ Lecturer in Social Policy \\ University of Wales, Swansea
}

MACMILLAN 
(C) Sheila Hunt and Anthea Symonds 1995

Foreword (C) Rosamund Bryar 1995

All rights reserved. No reproduction, copy or transmission of this publication may be made without written permission.

No paragraph of this publication may be reproduced, copied or transmitted save with written permission or in accordance with the provisions of the Copyright, Designs and Patents Act 1988, or under the terms of any licence permitting limited copying issued by the Copyright Licensing Agency, 90 Tottenham Court Road, London W1P 9HE.

Any person who does any unauthorised act in relation to this publication may be liable to criminal prosecution and civil claims for damages.

First published 1995 by MACMILLAN PRESS LTD

Houndmills, Basingstoke, Hampshire RG21 2XS and London

Companies and representatives

throughout the world

ISBN 978-0-333-60877-7

DOI 10.1007/978-1-349-13411-3

ISBN 978-1-349-13411-3 (eBook)

A catalogue record for this book is available from the British Library.

$\begin{array}{rrrrrrrrrr}10 & 9 & 8 & 7 & 6 & 5 & 4 & 3 & 2 & 1\end{array}$

$\begin{array}{llllllllll}04 & 03 & 02 & 01 & 00 & 99 & 98 & 97 & 96 & 95\end{array}$

Copy-edited and typeset by Povey-Edmondson Okehampton and Rochdale, England 
Dedicated to the memory of my much-loved sister, Maureen Elizabeth, who died on 31 December 1993, aged 32 years, mother of Sean, Fay and Madeleine.

Sheila C. Hunt 


\section{Contents}

List of Figures and Tables $\quad \mathbf{x}$

Foreword by Rosamund Bryar $\quad$ xi

Preface xiii

Acknowledgements xiv

Introduction $\quad \mathrm{xv}$

Searching for social meaning $\quad x v$

Studying midwives at work $\quad$ xvii

The research xviii

1 The Site of the Labour Process 1

Childbirth, sex and motherhood 2

Birth - From private to public 4

Making childbirth 'safe' 5

Defining safety 10

Natural birth, pain relief and social equality 12

$\begin{array}{ll}\text { Popular culture and hospital } & 14\end{array}$

2 The Management of Labour 18

Professions and semi-professions $\quad 18$

The professions: A man's world? 19

The semi-professions: A woman's world? 20

Power and distance $\quad 21$

The public image $\quad 22$

The problem of respectability 23

The road to respectability and status 24

Hospitalisation and the nursing connection 27

The idea of independence $\quad 29$

Professional power and authority 31

Female power and authority $\quad 32$

Completing the frame 36

3 Ethnography: Treating the Familiar as Strange 38

Studying the social world in its natural state 38

Researching continuity of care $\quad 41$ 
$\begin{array}{ll}\text { Getting started } & 42\end{array}$

Choosing the site $\quad 43$

Sampling $\quad 44$

$\begin{array}{ll}\text { The fieldwork stage } & 45\end{array}$

Participant or observer? $\quad 46$

Collecting, recording and thinking about the data 47

$\begin{array}{ll}\text { Ethical and other problems } & 49\end{array}$

$\begin{array}{ll}\text { Midwife and researcher } & 51\end{array}$

Analysis of the data $\quad 53$

4 Some Aspects of Labour Ward Culture 55

$\begin{array}{ll}\text { The setting } & 55\end{array}$

Midwife or researcher $\quad 58$

$\begin{array}{lr}\text { The labour ward office } & 59\end{array}$

Everyday rituals $\quad 63$

Statements and symbols $\quad 63$

The celivery room: the inner sanctum $\quad 67$

$\begin{array}{ll}\text { Notices } & 70\end{array}$

$\begin{array}{ll}\text { Autonomy and the midwife } & 73\end{array}$

5 All in a Day's Work $\quad 75$

$\begin{array}{ll}\text { Admissions } & 75\end{array}$

Birth: The labour process $\quad 80$

$\begin{array}{ll}\text { Terms of endearment } & 81\end{array}$

Emotional labour $\quad 82$

Sharing the work: real and unreal $\quad 85$

Rubber gloves and bloody arms $\quad 86$

Dirt and blood in midwifery practice $\quad 88$

Unacceptable dirt $\quad 89$

Criteria for moral evaluation of women and their partners 90

You can't trust a mother $\quad 92$

6 Organisation and Control 96

Getting through the work 96

The nigglers and labourers 98

Guessing and assessing $\quad 99$

$\begin{array}{ll}\text { Rules of admission } & 103\end{array}$

Writing notes and drinking tea 104

$\begin{array}{ll}\text { Aspects of communication } & 107\end{array}$

$\begin{array}{ll}\text { Enquiries and interruptions } & 110\end{array}$

7 Shifts and Handovers $\quad 113$

Continuity of care? $\quad 113$

$\begin{array}{ll}\text { A typology of handovers } & 114\end{array}$

$\begin{array}{ll}\text { Home time } & 121\end{array}$ 
Shifts, stresses and strains $\quad 122$

$\begin{array}{ll}\text { The agony of advocacy } & 128\end{array}$

Working at night 129

More tea? Enter Mrs Brown 133

8 Reflections and Conclusions 138

$\begin{array}{ll}\text { Culture and production } & 139\end{array}$

What is skill? $\quad 140$

The deskilling debate $\quad 142$

Deskilled or reskilled? $\quad 143$

Where next for midwives and midwifery? 144

$\begin{array}{ll}\text { Control? } & 144\end{array}$

$\begin{array}{ll}\text { Continuity of carer? } & 145\end{array}$

Choice? 147

Communication? 147

New site: Old problems? $\quad 148$

Women as winners? 149

Women as losers? 150

Midwives as winners or losers? 152

$\begin{array}{ll}\text { The future } & 154\end{array}$

Glossary of terms $\quad 155$

$\begin{array}{ll}\text { References } & 157\end{array}$

$\begin{array}{ll}\text { Index } & 164\end{array}$ 


\section{List of Figures and Tables}

Figures

1.1 Place of delivery, England and Wales, 1960

1.2 Place of delivery, England and Wales, 1970

1.3 Place of delivery, England and Wales, $1980 \quad 7$

1.4 Place of delivery, England and Wales, 1992

4.1 The labour ward office $\quad 60$

4.2 The notice-board $\quad 62$

4.3 The delivery room $\quad 68$

Tables

1.1 Primary causes of death in childbirth 9

1.2 Economic circumstances of mothers who died in
childbirth, 1937

8.1 Gendered skill hierarchies in a maternity unit 141

8.2 Reasons for arranging birth in hospital or at home 153 


\section{Foreword}

How do we interpret our world? How do we make sense of what is going on around us in an unfamiliar environment as a new member of staff, a student or as a woman making use of maternity services? How do we come to an understanding of the performance that as midwives, students, childbearing women or medical staff in which we are being asked to participate, where the scenes, roles, plot, characters and script have been largely 'prepared earlier'? Sheila Hunt and Anthea Symonds in this book have given us the tools to be able to undertake this interpretation and have provided a means of analysing the complex world of maternity care. The authors have undertaken an extremely valuable task in that they have, in the partnership of their writing, linked for us theory and practice. The descriptions by Sheila Hunt of the maternity units she studied will ring true for many readers. Yes, there will be nuances of differences for different midwives - from my experience I miss reference to knitting and to the particular type of humour found in maternity units!

But Sheila Hunt and Anthea Symonds have done a more important job than describing and analysing the work in these units - they have opened our eyes. How often have we stood back and observed the activities, notices, behaviours, talk, use of space and other factors in the world of the maternity unit? How often have we considered the extent to which our basic concepts about midwifery care are demonstrated in the social world of which we are a part, which we have helped to create and thus have the potential to change? The authors make clear, though, that such description has to be placed in the wider framework of society and the many factors which have influenced the role of the midwife and the provision of maternity services. They provide a comprehensive and challenging picture of that context which will be as disturbing to some readers as the description of the labour ward activities will be to others.

This, then, is not a book to be approached lightly - possibly it needs some sort of health warning. As with another, very different book, readers should be warned 'this book will change your life'! The authors provide evidence and analysis which challenge many of the complacent images that midwives hold of themselves and the care that they provide. By doing this they make a very important contribution to midwifery. At a time when midwives are being asked to examine their fundamental beliefs as changes are introduced to ensure greater continuity, choice and control, this book provides a means of understanding the present world of midwifery 
xii · Foreword

practice. It is only when everyone, including midwives, childbearing women, doctors, sociologists and managers, have an understanding of the past and present factors affecting maternity services that effective and realistic change can be made to these services. I urge everyone involved in the provision of maternity care, in receipt of maternity care and in research and teaching related to maternity care to read this book. Maternity services may never be the same again! 


\title{
Preface
}

This book is based on an ethnographic study of two hospital labour wards. The research was undertaken by Sheila Hunt in the late 1980s and early 1990s. She was a clinical midwife and more latterly a teacher of midwifery. Anthea Symonds became interested in both the study and in midwives when she was involved in joint planning of the first pre-registration midwifery education programme in Wales. Anthea is a sociologist with particular interest in occupational cultures and health policies. She read the first ethnographic study and was excited by its sociological potential and felt that there would be wider interest in the content.

At a series of successful 'double acts' at conferences and study days the ideas and concepts of the book were developed and refined. There was a strong feeling that this book would not go away despite the efforts they made to ignore it and their often waning interest in the topic. In 1993 they were forced to put pen to paper. Anthea wrote Chapters 1 and 2, while the remaining chapters were written by Sheila and are based on her research. The content will be controversial and may even upset some midwives. It appears that it is a tale that has to be told. Such studies can make uncomfortable reading but there is no doubt that exploring aspects of care in this detail cannot but help thinking midwives to consider midwifery practice more deeply and improve upon the care of women in childbirth.

\author{
Sheila C. Hunt
} ANTHEA SYMONDS 


\section{Acknowledgements}

We would like to thank:

- The women in the study who were willing to share their experience of birth.

- The midwives of Valley Maternity Hospital who were so willing to cooperate and eager to talk about themselves and their work.

- The midwives and students who at study days and conferences urged us to write this book because they believed that by looking at ourselves we could learn so much and improve care for women.

- The midwifery lecturers and Director of the Department of Nursing and Midwifery for their support.

- Paul Atkinson and Anne Murcott of the University College, Cardiff, who taught Sheila to be an ethnographer.

- Ruth Davies (WNB), who taught Sheila never silently to tolerate poor standards.

- And finally our long suffering families, David, Ruth and Thomas Hunt and Dr Keith Lewis.

Sheila C. Hunt ANTHEA SYMONDS 


\section{Introduction}

This book is about midwives, midwifery and women. It explores the social meaning of midwifery, considers birth as it happened in many British maternity hospitals in the late 1980s and offers an opportunity for past, present and future midwives to analyse aspects of their practice. Above all this is a study of women at work, and as such should prove of interest to sociologists and feminists.

The ethnographic study of two particular groups of midwives at work in two hospitals in the very recent past (1989) attempts to unravel their constructed occupational identity. It must be stressed that we are not setting up a generalist model of midwifery or claiming a universal theoretical understanding of what it means to be a midwife which would be applicable to everyone working anywhere. This is in the nature of an exploration into an understanding of the ways in which an identity of an occupational group is constructed in everyday practice. The study looks at the ways in which real women act in real situations in the everyday 'normal' hospital practice of midwifery. Evidently, this is not an account of a universal experience and some midwives will read this and fail to recognise any familiarity within the text, but equally there are many others to whom the situations, language and circumstances described here will strike a chord.

This book is in two main parts, the first part will be a 'scene-setting' exercise wherein the historical, political and social background to the construction of this specific occupational group and the site of its working practice is set out as well as a description of the methodology involved. The second part consists of the ethnographic study of the labour wards, which must be read within the theoretical framework set out in the first two chapters.

\section{- Searching for social meaning}

The fundamental argument underlying this book is that descriptions of an occupation such as 'midwife' have no intrinsic meaning of their own. To be a midwife is a cultural and historical experience. This experience will differ from culture to culture and over time. To be a midwife in a Bronze Age encampment, or in the court of a Stuart monarch, in the slums of nineteenth-century Manchester and in a modern hospital are different 
experiences which carry different meanings. A social meaning is one placed upon a label such as 'midwife' by a variety of social and public discourses and constructed by social policies. How can we 'understand' what it means to be a midwife in the last decade of the twentieth century ? Oral histories which record the remembered life experiences of midwives working in the past (Leap and Hunter, 1993) show vividly what this meant to individual women, but what does the occupational label of 'midwife' mean in society and how is it constantly reinforced in everyday practice? This is the object of our search.

The social meaning of a defined occupation is always in process, it is dynamic and ever-changing and can only be captured at a specific juncture as a snapshot captures a moment. This identity has to be constantly reinforced and reconstructed but must always retain a referral point of recognition for the practitioners to feel a sense of security in belonging. The ways in which an occupational identity is constructed and reinforced include work practices and strategies of control, use of language and public representations of this image. This is an essentially interpretive exercise involving the values and perceptions of the observer and the observed.

Recently sociologists have become very interested in the ways in which the professions of surgery and dentistry have constructed a social meaning (Fox, 1992; Nettleton, 1992). Midwifery is especially interesting to a sociologist not only because it is a gendered occupation but also because it operates in a private female sphere which has historically been shrouded in sexual mystery and societal taboos.

The social meaning of midwifery as an occupation cannot be divorced from the social meaning of childbirth, so the first step in this study is to look at the changing construction of the labour process itself. It is significant, we feel, that the very phrase 'labour process' is used to describe both the activity of childbirth and the organisation of work in an industrial economy.

The re-siting of birth from the private world of the home to the public world of hospital mirrors the change in the economic mode from private home-based handicrafts or agricultural work and small family-owned enterprises to large-scale factory production which has occurred since the advent of capitalist industrialisation.

The description of the hospital way of birth as resembling an assembly line is one which is often evoked by women and it is this comparison with an industrial organisation of labour which our study takes up.

A historical analysis of the changed role of the hospital midwife as the manager of the labour of others with the child as the object of production is set out in the first chapter. A wider understanding of the evolution of this role can be gained by looking at the specific identity of midwives as women working within this female sphere of production.

The hospital work practice takes place within a set of hierarchical and inter-professional relationships, therefore the second step in the 
exploration is to look at the strategies which midwives and the other professional groups such as obstetricians and GPs have employed in order to gain control of the labour process. When this theoretical background has been sketched in, the study itself will be presented in order to pose an interpretation of the ways in which all these themes come together in everyday life and work.

\section{- Studying midwives at work}

The ethnographic studies which form the focus of this book were conducted in two British maternity hospitals during the latter part of 1989. The researcher was, and is, a midwife and undertook the research in her capacity as 'a student of research at the university'.

The two maternity units were quite typical examples of the provision of maternity services at that time and both formed part of the larger District General Hospitals. In 1989, as in subsequent years, 98 per cent of women gave birth to their babies in NHS hospitals (OPCS, 1991).

The usual practice was for women who thought they might be pregnant to consult their general practitioner (GP). The GP would write to the District General Hospital for an appointment for the woman to attend the booking clinic. This name derived from the time when a bed had to be 'booked' for the birth. The woman might see her GP again but more usually would next be seen at the antenatal clinic at the hospital. At this first visit the woman and her pregnancy would be assessed and arrangements would be made for 'shared care'. Shared care usually meant that the woman would visit her GP and then the hospital antenatal clinic on alternate occasions. Sometimes the woman would meet the midwife in her own home (another booking visit) or at the GP's surgery or health centre.

At the hospital it was usual to meet the antenatal clinic midwife and perhaps some student midwives. When the woman telephoned the hospital or just arrived, at the time of labour, it was likely that she would not have seen or spoken to the midwife before.

At the end of the 1980 s midwives tended to stick fairly rigidly to their areas', i.e. the hospital antenatal clinic, the hospital labour ward, day duty or night duty. Generally only relatively junior midwives and students would rotate from one department to another and then only rarely to a community midwifery setting.

All the midwives in this study were employed by the Health Authorities and had a contract of employment to work either in hospital or in the community. All were salaried, some were part time (15-30 hours per week) and the rest worked full time at 37.5 hours per week. There were no temporary or bank staff employed and all were provided with uniforms, paid sick leave and thirty five days holidays per year. 


\section{The research}

The research was conducted in two hospitals over a six month period during the winter and spring months. The hospitals were similar in design and in their state of repair and decoration although they were operated by two different health authorities.

Chapter 3 includes a detailed description of the methodology used for the study and considers the advantages and disadvantages of ethnography as a research method. It considers the ethical difficulties associated with the method and the issue of a midwife studying midwives.

The key themes that emerge from the study are presented in Chapters 4, 5, 6 and 7. Chapter 4 'Some aspects of labour ward culture' provides a detailed description of the setting of the hospital with the reader invited on a guided tour of the key areas where the observations took place. There is a detailed description of the multi functional 'office' with its unique features that formed part of one unit. There is also a description of the 'inner sanctum' or delivery room with an explanatory diagram. Further details of the environment are described with references to 'the notices' that formed such an important part of the delivery suite.

Chapter 5 is called 'All in a day's work' and considers the hospital admission procedure, the process of birth, and explores attitudes to blood and dirt. Admission in labour was observed to be a very routinised procedure where the midwife was seen to take control of the childbirth event. This control was clarified and confirmed during the birth of the baby, where the description includes the use of ritualistic phrases and expressions. The final section of this chapter considers the criteria adopted by midwives for the 'moral evaluation' of women and their partners.

In Chapter 6 (called 'Organisation and control') the reader is introduced, in the sections 'Getting through the work' and in 'Writing notes and drinking tea,' to the method employed by midwives to control the working environment. The study then considers the organisation of labour ward work including the control of admissions to the delivery suite, the dissemination of information and how the news of birth was spread. The use of terminology is explored especially the terms 'nigglers and labourers' where women were labelled according to the efficiency of the production process. This is further developed in 'Aspects of communication'.

Chapter 7 is called 'Shifts and handovers' and explores aspects of working shifts and the methods used to exchange information. It also studies other aspects of midwifery care. A typology of handovers is offered with analysis and comment. The difficulties associated with running a twenty-four-hour service are considered with attention being given to the unique features of night duty.

Chapter 8 reviews the key themes of Chapters 4, 5, 6 and 7 and debates the possible scenarios for midwifery care in the next decade. 
The work of a midwife in the 1990s is inspiring, challenging, demanding, emotionally draining and absolutely unique. The study presented does not lay any claims for universality, it does not offer quick-fix answers for improving care. It aims to present information and analysis and seeks not to sit in judgement on the midwives at work in these hospitals. It is intended as a starting-point for analysis and constructive thought into the complex issues of care of women and their babies at a crucial time of their lives. 